\title{
Immunological and ultrastructural studies in acute biphenotypic leukaemia
}

\author{
V Shetty, A Chitale, E Matutes, V Buccheri, R Morilla, D Catovsky
}

\begin{abstract}
Aims-To compare the sensitivity of the ultrastructural method to detect myeloperoxidase (MPO) with light microscopy and immunocytochemistry using an antiMPO antibody; to examine the expression of lymphoid antigens in relation to MPO activity in blast cells from cases of biphenotypic leukaemia.
\end{abstract}

Methods-Blast cells from 14 cases of biphenotypic acute leukaemia were analysed. Immunological markers were performed by single or double immunofluorescence staining on a flow cytometer. The presence of MPO was determined by light microscopy, electron microscopy on fixed and unfixed cells, and by immunoalkaline phosphatase with an anti-MPO antibody. The immunogold method was applied at the ultrastructural level to assess the expression of lymphoid and myeloid antigens at the same time as the MPO activity.

Results-Six of the 14 cases were initially classified as acute lymphoblastic leukaemia (ALL) and eight as acute myeloid leukaemia (AML). MPO activity was shown at the ultrastructural level in $4-99 \%$ blasts from all cases. Six of the 14 were MPO negative by light microscopy and three of these were negative with the antibody anti-MPO. Coexpression of lymphoid antigens (CD19, CD10, or CD2) and MPO was shown by the immunogold method in four out of 11 cases; in seven cases the blasts coexpressed myeloid antigens (CD13, CD33) and MPO.

Conclusions-Electron microscopy is more sensitive for showing MPO than light microscopy and immunocytochemistry; the immunogold method combined with MPO used at the ultrastructural level can help to define the cell lineage involved in biphenotypic leukaemia by highlighting the myeloid component defined by MPO.

$(\Im$ Clin Pathol 1993;46:903-907)

Acute leukaemias result from the clonal expansion of haemopoietic progenitor cells with variable degrees of myeloid or lymphoid commitment. A precise definition of myeloid or lymphoid features on blast cells is necessary as current treatment is given according to the main lines of differentiation.
An increasing number of reports have documented, in the past few years, cases of acute leukaemia in which the cells have both lymphoid and myeloid characteristics. These have been designated as hybrid, biphenotypic, or mixed lineage leukaemias. ${ }^{1-7}$ The simultaneous $^{258}$ or sequential $^{910}$ expression of antigens from more than one lineage in leukaemic cells presents diagnostic problems and also raises the issue of the cell origin of these leukaemias.

Electron microscopy has been valuable for the analysis of ultrastructural details which could not be resolved by light microscopy. ${ }^{11}$ The possibility of combining ultrastructural cytochemistry and immunological markers using a colloidal gold method provides a means that the simultaneous expression of a myeloid or lymphoid surface antigen and a cytoplasmic enzyme (such as myeloperoxidase) can be examined in single cells.

\section{Methods}

Out of 205 newly diagnosed cases of acute leukaemia we selected $14(6.5 \%)$ diagnosed as biphenotypic by the expression of two or more differentiation antigens from two separate lineages. ${ }^{12}$ These cases were studied in more detail using immunoelectron microscopy and ultrastructural cytochemistry and are the subject of this report.

Peripheral blood and bone marrow films were stained with May-Grünwald Giemsa and for the cytochemical reactions of myeloperoxidase, Sudan black B, and $a-$ naphthyl acetate esterase with and without sodium fluoride inhibition.

Immunological studies were carried out on mononuclear cell suspensions obtained by density gradient centrifugation (Lymphoprep; Nycomed Pharma). A panel of monoclonal antibodies to $\mathrm{T}$ cell, B cell, myeloid, stem cell, erythroid, and megakaryoblastic antigens was used and the presence of surface or cytoplasmic antigens was detected by indirect immunofluorescence and immunocytochemistry, respectively. Details of these methods are given elsewhere. ${ }^{13}$

Myeloperoxidase was investigated using three different electron microscopic methods which differ in the way the cells are prepared before the MPO reaction is carried out.

(1) Graham and Karnovsky's method ${ }^{14}$ : the cells are fixed in $3 \%$ glutaraldehyde in $0.1 \mathrm{M}$ phosphate buffer for 30 minutes at $4^{\circ} \mathrm{C}$ and then incubated in diaminobenzidine (DAB) containing $1 \%$ hydrogen peroxide ( $\mathrm{pH} 7 \cdot 4)$. 
Table 1 Immunological markerst (percentage of positive blasts)

\begin{tabular}{|c|c|c|c|c|c|c|c|c|c|c|c|}
\hline \multirow{2}{*}{$\begin{array}{l}\text { Case } \\
\mathrm{No}^{\star}\end{array}$} & \multicolumn{4}{|c|}{ Tlymphoid markers } & \multicolumn{4}{|c|}{ B lymphoid markers } & \multicolumn{3}{|c|}{ Myeloid markers } \\
\hline & $C D 2$ & $c C D 3$ & $C D 5$ & $C D 7$ & $C D 10$ & $C D 19$ & $c C D 22$ & $C D 24$ & $C D 13$ & $C D 33$ & anti-MPO \\
\hline 1 & 11 & 0 & 0 & 1 & 93 & 89 & 8 & 90 & 79 & 3 & 8 \\
\hline 2 & 0 & 0 & 0 & 0 & 83 & 94 & 0 & 0 & 86 & 6 & 0 \\
\hline 3 & 5 & 0 & 0 & 0 & 82 & 96 & 11 & 0 & 86 & 86 & 6 \\
\hline 4 & 13 & 0 & 0 & 10 & 26 & 82 & 74 & 0 & 46 & 34 & 0 \\
\hline 5 & 3 & 5 & 0 & 2 & 78 & 52 & 0 & 0 & 0 & 63 & 2 \\
\hline 6 & 0 & 0 & 4 & 3 & 39 & 89 & 0 & 92 & 80 & 0 & 5 \\
\hline 7 & 21 & 0 & 0 & 0 & 64 & 0 & 80 & 98 & 68 & 97 & 10 \\
\hline 8 & 0 & 0 & 0 & 11 & 28 & 5 & 28 & 3 & 38 & 16 & 21 \\
\hline 9 & 17 & 0 & 0 & 0 & 26 & 64 & 3 & 0 & 61 & 37 & 29 \\
\hline 10 & 4 & 0 & 0 & 0 & 4 & 86 & 65 & 40 & 74 & 44 & 8 \\
\hline 11 & 90 & 0 & 0 & 67 & 0 & 0 & 0 & 0 & 97 & 80 & 90 \\
\hline 12 & 79 & 77 & 85 & 12 & 2 & 0 & 0 & 0 & 46 & 60 & 4 \\
\hline 13 & 30 & 26 & 72 & 60 & 0 & 0 & 0 & 0 & 8 & 71 & 28 \\
\hline 14 & 74 & 0 & 68 & 0 & 3 & 0 & 0 & 0 & 45 & 82 & 15 \\
\hline
\end{tabular}

*Cases $1-6$ were classified initially as ALL and cases 7-14 as AML.

$\uparrow \mathrm{TdT}$ was positive in all cases; myeloid markers CD14 and CD11c were negative in all cases. Molecular analyses were performed in three ALL cases (1,3, and 4) and in six AML cases (7 and 9-13)

(2) The method of Roels et al ${ }^{15}$ : the unfixed cells are incubated in DAB mixture containing 3\% hydrogen peroxide $(\mathrm{pH} 7 \cdot 2)$ for 30 minutes in the dark and then fixed in $1.25 \%$ glutaraldehyde in $0 \cdot 1 \mathrm{M}$ phosphate buffer $(\mathrm{pH}$ $7 \cdot 4$ ) for 30 minutes at $4^{\circ} \mathrm{C}$.

(3) A method after Breton Gorius et al ${ }^{16}$ : 10 minutes of fixation with $1 \cdot 25 \%$ glutaraldehyde in Gey's buffer, before the MPO reaction. This buffer preserves the polymerisation of tubulin and maintains good morphology. This was used mainly with the immunogold procedure.

For immunogold staining, mononuclear cells were adjusted to a concentration of $25 \times 10^{6}$ cells $/ \mathrm{ml}$. The cell suspension (200 $\mu \mathrm{l})$ was incubated with the appropriate monoclonal antibodies for 30 minutes at room temperature. The monoclonal antibodies used were: CD2 (RFT11; gift from Professor G Janossy, Royal Free Hospital); CD19 (antiLeu12, Becton-Dickinson); CD10 (J5); CD13 (My7); and CD33 (My9, Coulter Clone). The cells were washed three times with phosphate buffered saline containing $1 \%$ decomplemented human serum, $A B \quad 1 \%$ bovine serum albumin, and $0.2 \%$ sodium

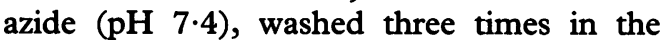
gold buffer, and incubated with a goat antimouse Ig labelled with $30 \mathrm{~nm}$ colloidal gold particles (Janssen, Life Sciences, Belgium) for 1 hour at room temperature. After three washes with the gold buffer the cells were fixed in $1.25 \%$ glutaraldehyde in phosphate buffered saline for 30 minutes for electron microscopic examination of morphology and in Gey's buffer for 10 minutes for the MPO reaction. Subsequently, post-fixation, dehydration, and embedding were performed according to the standard methods. ${ }^{17}$

Molecular analyses were performed in

Table 2 Double marker studies by FACS

\begin{tabular}{ll}
\hline Case No & $\begin{array}{l}\text { Double markers by } \\
\text { immunofluorescence }\end{array}$ \\
\hline 3 & CD13 + CD10: 80\% \\
4 & CD33 + CD19: 57\% \\
& CD13 + CD19: 40\% \\
7 & CD13 + CD10: $14 \%$ \\
9 & CD33 + CD19: 61\% \\
12 & CD13 + CD10: $50 \%$ \\
\hline
\end{tabular}

three cases of ALL and six of AML classified as biphenotypic. DNA was extracted from mononuclear cells, and procedures for Southern blot analysis have been described before. ${ }^{12}$

\section{Results}

LIGHT MICROSCOPY, MORPHOLOGY, AND CYTOCHEMISTRY

Blast cells from 10 out of 14 cases were poorly differentiated with a high nuclear: cytoplasmic ratio and no granules. According to FAB criteria, ${ }^{18}$ six cases were initially classified as lymphoblastic (ALL) and eight cases as acute myeloid leukaemia (table 1). In cases $6,9,10$, and 13 there was a mixture of two morphologically distinct cell populations, some resembling lymphoblasts - small in size and with a high nuclear:cytoplasmic ratioand larger ones resembling myeloblasts or monoblasts with more abundant cytoplasm and identifiable granules in some of them. Sudan black or myeloperoxidase were positive in all the AML cases; in two cases only $4 \%$ of blast cells were positive; this ranged from $29 \%$ to $100 \%$ in the others.

\section{IMMUNOPHENOTYPING}

All cases classified as biphenotypic were $\mathrm{TdT}$ positive and coexpressed lymphoid and myeloid antigens (table 1). The blast cells in cases 1-10 were positive with $B$ markers (CD10, CD19, and CD24 or cCD22) and cases 11-14 showed T markers (CD2, cCD3, and CD5 or CD7). All of them also expressed myeloid antigens (CD13 or CD33) or were positive with anti-MPO, or both.

Dual colour immunofluorescence carried out in five cases showed that B lymphoid and myeloid antigens were expressed in four and $T$ lymphoid and myeloid antigens in one case (table 2).

\section{ELECTRON MICROSCOPIC MORPHOLOGY}

The blast cells had high nuclear:cytoplasmic ratios with predominantly dispersed nuclear euchromatin and condensation of the nuclear chromatin towards the periphery. In four cases $(6,9,10,13)$ two distinct populations of blasts were recognised, and this was also shown by light microscopy. The larger blast cells had an irregular nuclear outline with 


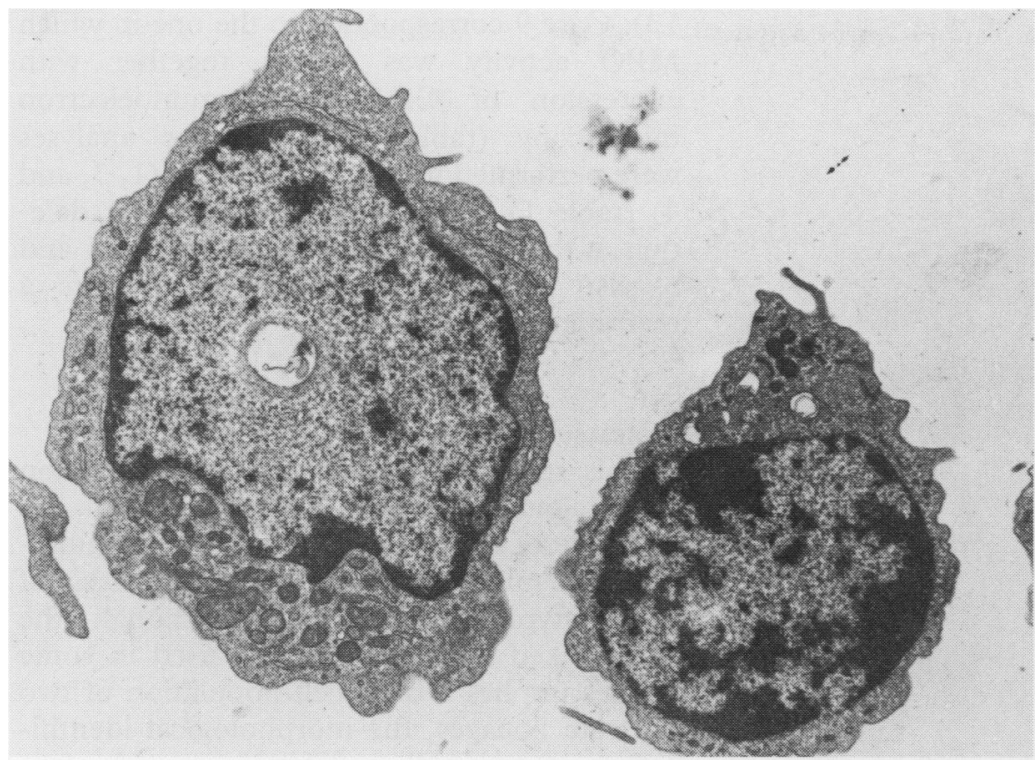

Figure 1 Two morphologically distinct blast cells: large blast cells with relatively condensed chromatin and a fair number of cytoplasmic organelles and small blast cells with heavy chromatin condensation, thin cytoplasm, and paucity of organelles (uranyl acetate and lead citrate staining).

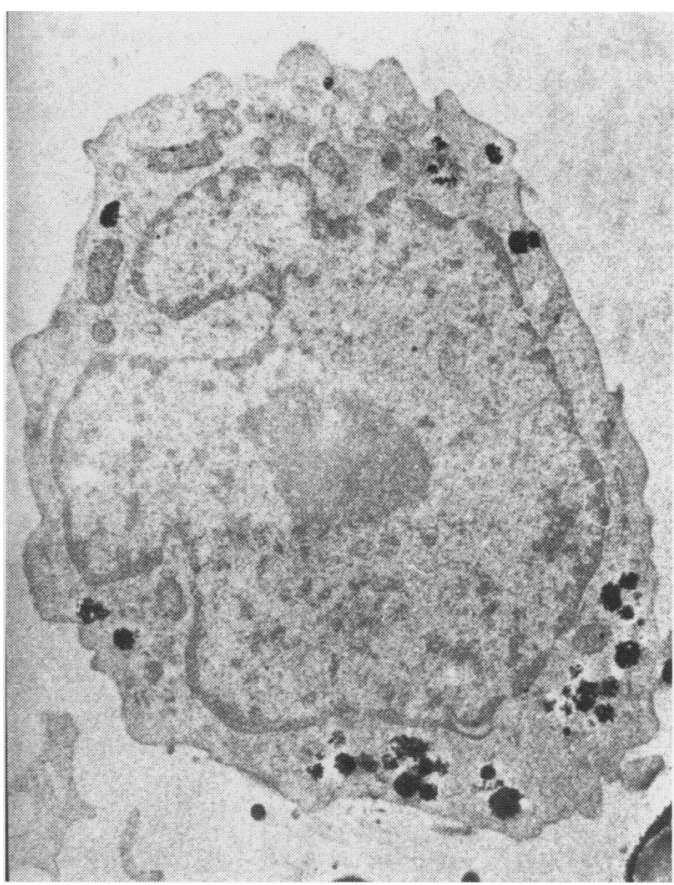

Figure 2 MPO activity localised in small and large granules of a blast cell (unstained section).

In the six cases classified initially as ALL, with MPO negative by light microscopy, the MPO positive granules were small by electron microscopy. These granules were either scattered throughout the cytoplasm or clustered in the Golgi zone (fig 2). In the four cases with an admixture of blasts of two sizes, MPO positivity was seen in the large blasts in all the cases and in the small, lymphoid-looking blasts in two cases $(9,13)$. We observed no difference in the localisation of MPO activity and in the percentage of MPO positive blasts with the three methods used at electron microscopy.

\section{IMMUNOELECTRON MICROSCOPY}

Surface marker expression by immunogold staining in combination with ultrastructural cytochemistry was carried out in 11 cases (table 4). In four $(5,7,9,12)$ blasts showing stration of MPO by electron microscopy was critical to qualify this case as biphenotypic as only one myeloid antigen (CD13) was positive. In cases 4 and 5 electron microscopy was also the only method to demonstrate MPO as this was negative by light microscopy and anti-MPO (table 3).

In the cases classified as AML MPO activity was localised in small and large granules.

Table 3 Comparison of MPO by three methods (percentage of positive blasts)

\begin{tabular}{lccc}
\hline $\begin{array}{l}\text { Case } \\
\text { No }\end{array}$ & $\begin{array}{l}\text { Light } \\
\text { microscopy }\end{array}$ & $\begin{array}{l}\text { Electron } \\
\text { microscopy }\end{array}$ & $\begin{array}{l}\text { Anti- } \\
\text { MPO }\end{array}$ \\
\hline 1 & 0 & 7 & 8 \\
2 & 0 & 5 & 0 \\
3 & 0 & 5 & 6 \\
4 & 0 & 4 & 0 \\
5 & 0 & 7 & 2 \\
6 & 0 & 6 & 5 \\
7 & 6 & 54 & 10 \\
8 & 55 & 90 & 21 \\
9 & 29 & 30 & 29 \\
10 & 4 & 16 & 8 \\
11 & 100 & 99 & 90 \\
12 & 4 & 42 & 4 \\
13 & 15 & 89 & 28 \\
14 & 6 & 33 & 15 \\
\hline
\end{tabular}

Table 4 Simultaneous demonstration of ultrastructural MPO and membrane markers

\begin{tabular}{|c|c|c|}
\hline $\begin{array}{l}\text { Case } \\
\text { No }\end{array}$ & $\begin{array}{l}\text { MPO plus } \\
\text { lymphoid markers }\end{array}$ & $\begin{array}{l}\text { MPO plus } \\
\text { myeloid markers }\end{array}$ \\
\hline 1 & $\begin{array}{l}\mathrm{CD10(+)/MPO(-):} 63^{\star} \\
\mathrm{CD} 19(+) / \mathrm{MPO}(-): 55\end{array}$ & $\begin{array}{l}\mathrm{CD} 13(+) / \mathrm{MPO}(-): 72^{\star} \\
\mathrm{CD} 13(+) / \mathrm{MPO}(+): 5\end{array}$ \\
\hline 2 & $\begin{array}{l}\text { CD10(+)/MPO (-): } 90 \\
\text { CD19(+)/MPO }(-): 75\end{array}$ & $\mathrm{CD13}(+) / \mathrm{MPO}(-): 42$ \\
\hline 3 & $\begin{array}{l}\text { CD10(+)/MPO }(-): 60 \\
\text { CD19(+)/MPO }(-): 65\end{array}$ & \\
\hline 4 & CD19(+)/MPO $(-): 64$ & \\
\hline 5 & $\begin{array}{l}\text { CD10(+)/MPO }(-): 60 \\
\text { CD10(+)/MPO(+): } 9 \\
\text { CD19(+)/MPO(-): } 62 \\
\text { CD19(+)/MPO }(+): 9\end{array}$ & $\begin{array}{l}\mathrm{CD} 33(+) / \mathrm{MPO}(-): 22 \\
\mathrm{CD} 33(+) / \mathrm{MPO}(+): 16\end{array}$ \\
\hline 6 & CD19(+)/MPO $(-): 79$ & $\begin{array}{l}\text { CD33(+)/MPO(-): } 65 \\
\text { CD33(+)/MPO(+): } 39\end{array}$ \\
\hline 7 & $\begin{array}{l}\mathrm{CD} 10(+) / \mathrm{MPO}(-): 42 \\
\mathrm{CD} 10(+) / \mathrm{MPO}(+): 8 \\
\text { CD19(+)/MPO }(-): 36 \\
\mathrm{CD} 19(+) / \mathrm{MPO}(+): 24\end{array}$ & $\begin{array}{l}\text { CD13(+)/MPO(-): } 80 \\
\text { CD13(+)/MPO }(+): 32\end{array}$ \\
\hline 9 & $\begin{array}{l}\text { CD10(+)/MPO (-): } 47 \\
\text { CD19(+)/MPO(-): } 40 \\
\text { CD19(+)/MPO }(+): 18\end{array}$ & $\begin{array}{l}\text { CD13(+)/MPO(-): } 40 \\
\text { CD13(+)/MPO(+): } 25\end{array}$ \\
\hline 10 & CD19(+)/MPO $(-): 79$ & CD33(+)/MPO(-): 30 \\
\hline 12 & $\begin{array}{l}\mathrm{CD} 2(+) / \mathrm{MPO}(-): 66 \\
\mathrm{CD} 2(+) / \mathrm{MPO}(+): 28\end{array}$ & $\begin{array}{l}\text { CD33(+)/MPO(-): } 59 \\
\text { CD33(+)/MPO }(+): 36\end{array}$ \\
\hline 14 & $\mathrm{CD} 2(+) / \mathrm{MPO}(-): 79$ & $\begin{array}{l}\text { CD33(+)/MPO (-): } 65 \\
\text { CD33(+)/MPO }(+): 39\end{array}$ \\
\hline
\end{tabular}

^Percentage of positive blasts. 
Figure 3 Single cell exhibiting MPO activity (thick arrow) and gold labelling with CD19 (thin arrow) (unstained section).

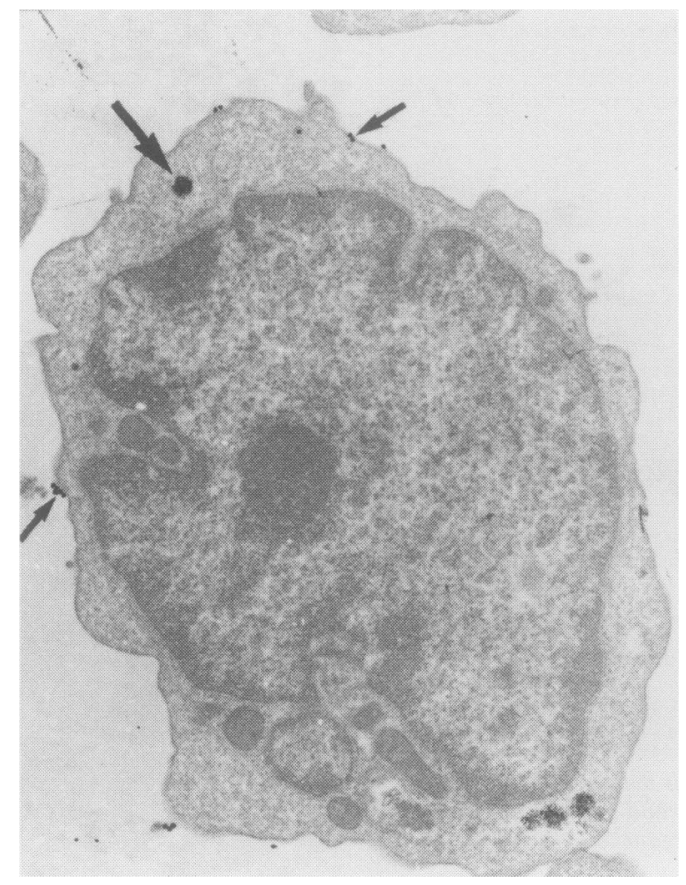

MPO activity expressed lymphoid antigens (CD19, CD10, or CD2) (fig 3); in the remaining seven cases lymphoid antigen expression was confined to MPO negative blasts (fig 4). MPO negative blasts expressing CD10 and CD19 showed a much greater number of gold particles on their surface (fig 4) than MPO positive blasts expressing a lymphoid marker (fig 3). Coexpression of myeloid markers and MPO activity was seen in seven cases (table 4$)$. Three of these $(1,5$, and 6) had initially been classified as ALL.

\section{MOLECULAR ANALYSIS}

Immunoglobulin or TCR genes investigated in six cases of biphenotypic AML ( 7 and 9-13) (table 1) showed that three had rearrangements of $\mathrm{Ig}$ and TCR genes $(9,10$,

Figure 4 MPO negative blast cell labelled for CD19 (arrow) (unstained section).
13). Case 9 corresponded to the one in which MPO activity was shown together with expression of CD19 by immunoelectron microscopy (table 4). Molecular analyses were performed in three ALL cases $(1,3$, and 4) (table 1). All had rearrangement or deletion of the Ig heavy chain genes. Cases 1 and 3 also exhibited the TCR genes in a rearranged configuration.

\section{Discussion}

In this study we addressed the coexpression of myeloid or lymphoid antigens with the presence of MPO using a sensitive immunoelectron microscopy technique in cases of biphenotypic leukaemia. ${ }^{1348}$ Although the term mixed lineage leukaemia used in some studies implies a blast cell population of two separate lineages, the morphological identification of two cell populations is not often seen. Four out of our 14 cases of biphenotypic leukaemia had blast cells of two sizes when peripheral blood films were examined, and this was confirmed by ultrastructural analysis (fig 1). MPO positive granules were found in the large blasts of the four cases and also in the small blasts in two of them. In the remaining 10 cases the diagnosis of biphenotypic leukaemia was not suspected by morphological detail alone but was demonstrated immunophenotypically.

Ultrastructural cytochemistry had an important role in defining the biphenotypic nature of the blasts in some of the cases. In case 2, the demonstration of lymphoid markers was associated with only one myeloid antigen (CD13). According to our scoring system, ${ }^{12}$ this case would not have been classified as biphenotypic because it showed expression of a single myeloid antigen. The presence of MPO by ultrastructural analysis, however, led to the reclassification of this case as biphenotypic. In case 4 ultrastructural cytochemistry was needed to confirm myeloid differentiation in addition to myeloid antigens as the enzyme MPO was not detected by any other method.

Previous reports have shown that ultrastructural cytochemistry is more sensitive than light microscopy to detect MPO. ${ }^{19-23} \mathrm{We}$ have shown that electron microscopy may also, in some circumstances, be more sensitive than anti-MPO, which detects the active enzyme as well as the pro-enzyme form of peroxidase. ${ }^{13}$ The failure of light microscopy to demonstrate MPO in some cases relates to the localisation of MPO activity in small granules visible only at electron microscopy. Electron microscopic cytochemistry is useful to show myeloid differentiation in AML, including $\mathrm{MPO}^{22}$ and, as shown here, in cases defined as biphenotypic.

The combination of ultrastructural cytochemistry and immunogold staining using electron microscopy enabled us to define more precisely whether the myeloid and lymphoid features are present in the same blast cells or in two different populations. The coexpression of lymphoid antigens and MPO 
was clearly shown in four cases initially classified as AML. Our cases could be subdivided in two groups: (1) those in which a proportion of MPO positive blasts expressed either $B$ or $T$ lymphoid antigens. This has been shown by others by the expression of CD19 and CD24, along with MPO activity by light and electron microscopy 124524 ; (2) cases in which MPO was present in cells bearing myeloid antigens but absent in cells showing lymphoid markers. At present, we do not know whether these represent distinct subgroups of biphenotypic leukaemias. Double labelling using FACS analysis cannot indicate whether both antigens and MPO are present on the same cell. On the other hand, in three cases initially classified as $\operatorname{ALL}(1,5$, and 6$)$ the coexpression of myeloid antigens and MPO was shown in $5 \%-39 \%$ of cells (table 4).

It is apparent from this study that the cases which should be investigated with the techniques described here are those which are TdT positive AML and ALL (always TdT positive) which express one or more myeloid antigens. ${ }^{12}$

Analysis of the number of gold particles attached to the cell membrane relates to antigen density expression. The amount of labelling with monoclonal antibody against lymphoid antigens was less intense in MPO positive blasts coexpressing a lymphoid marker than in MPO negative blasts. This suggests that the 'lymphoid-looking' MPO negative blast may be more differentiated towards the lymphoid lineage than the blasts which are MPO positive and express lymphoid antigens. This type of observation, made possible by the combined ultrastructural method used here, can provide an objective approach to study the cellular components in biphenotypic leukaemia.

This work was supported by the Leukaemia Research Fund (VS) and CAPES, Brazil (VB), and by the Cancer Research Campaign (EM, RM). We are grateful to Wanda Malinowsk for typing the manuscript.

1 Neame PB, Soomboonsrup P, Browman G, et al. Simultaneous or sequential expression of lymphoid and myeloid phenotypes in acute leukemia. Blood 1986;65: 142-8.

2 Pui CH, Dahl GV, Melvin S, et al. Acute leukaemia with mixed lymphoid and myeloid phenotypes. $\mathrm{Br} f$ Haematol 1984;56:121-30.

3 Childs CC, Ginsberg CH, Walters RS, et al. Myeloid surface antigen-positive acute lymphoblastic leukemia (My + ALL): Immunophenotypic, ultrastructural and molecular characteristics. Leukemia 1989;1:644-52.
4 Kantarjian HM, Ginsberg $\mathrm{CH}$, Yee Garland, Huh Y, Freirech EJ, Stass SA. Mixed lineage leukemia revisited: acute lymphocytic leukemia with myeloperoxidase positive blasts by electron microscopy. Blood 1990;76: 808-13.

5 Guyotat D, Campos L, Shi ZH, et al. Myeloid surface antigen expression in adult acute lymphoblastic leukemia. Leukemia 1990:1:664-6.

6 Akashi K, Shibuya T, Harada M, et al. Acute 'bilinealbiphenotypic' leukaemia. Br f Haematol 1990;74:402-7.

7 Cross AH, Goorha RM, Nuss R, et al. Acute myeloid Cross AH, Goorha RM, Nuss R, et al. Acute myeloid
leukemia with T-lymphoid features: a distinct biologic and clinical entity. Blood 1988;72:579-87.

8 Lavabre-Bertrand $\mathrm{T}$, Vannereau $\mathrm{H}$, Donadio $\mathrm{D}$, et al. Interest of simultaneous ultrastructural characterisation of morphology, cytochemistry and immune phenotype in a case of putative hybrid acute leukaemia. Eur $f$ Haematol 1989;42:202-6.

9 Stass S, Mirro J, Melvin S, Pui CH, Murphy SB, Williams D. Lineage switch in acute leukemia. Blood 1984;64: 701-6.

10 Murphy SB, Stass S, Kalwinsky D, Rivera G. Phenotypic conversion of acute leukaemia from $T$-lymphoblastic to conversion of acute leukaemia from T-lymphoblastic to
myeloblastic induced therapy with 2 -deoxycoformycin myeloblastic induced therap

11 Campana D, Hansen-Hagge TE, Matutes E, et al. Phenotypic, genotypic, cytochemical and ultrastructural characterization of acute undifferentiated leukemia. Leukemia 1990;12:620-4.

12 Buccheri V, Matutes E, Dyer MJS, Catovsky D. Lineage commitment in biphenotypic acute leukemia. Leukemia 1993;7:919-27.

13 Buccheri V, Shetty V, Yoshida N, Morilla R, Matutes E, Catovsky $\mathrm{D}$. The role of an anti-myeloperoxidase antibody in the diagel ody in the diagnosis and classification of acute electron microscopy cytochemi

14 Graham RC, Karnovsky MJ. The early stages of absorption of injected horseradish peroxidase in the proximal tubules of mouse kidney: ultrastructural cytochemistry by a new technique. $\mathcal{f}$ Histochem Cytochem 1966;14 291-302.

15 Roels F, Wisse E, De Brest B, Van der Meulen J Cytochemical discrimination between catalases and peroxidases using diaminobenzidine. Histochemistry 1975;41:281-311.

16 Breton-Gorius J, Vanhaeke D, Pryzwansky KB, et al. Simultaneous detection of membrane markers with monoclonal antibodies and peroxidase activities in leukaemia: ultrastructural analysis using a new method of fixation preserving the platelet peroxidase $\mathrm{Br} f$ of fixation preserving the

17 Polli N, O'Brien M, Tavares de Castro J, Matutes E, San Miguel JF, Catovsky D. Characterization of blast cells in chronic granulocytic leukaemia in transformation, acute myelofibrosis and undifferentiated leukaemia. I Ultrastructural morphology and cytochemistry. $\mathrm{Br} f$ Haematol 1985;59:277-96.

18 Bennett J, Catovsky D, Daniel M-T, et al. Proposals for the classification of the acute leukaemias (FAB Cooperative Group). Br $¥$ Haematol 1976;33:451-8.

19 Marie JP, Vernant JP, Dreyfus B, Breton-Gorius J. Ultrastructural localization of peroxidases in "undifferentiated" blasts during the blast crisis of chronic granuentiated" blasts during the blast crisis of chronic gra

20 Pui CH, Behm FG, Kalwinsky DK, et al. Clinical significance of low levels of myeloperoxidase positivity in childhood acute nonlymphoblastic leukemia. Blood 1987;70:51-4.

21 Vainchenker $\mathrm{W}$, Villeval JL, Tabilio A, et al. Immunophenotype of leukemic blasts with small peroxidase positive granules detected by electron microscopy. Leukemia 1988;2:274-81.

22 Matutes E, Pombo de Oliveira M, Foroni L, Morilla $R$ Catovsky D. The role of ultrastructural cytochemistry and monoclonal antibodies in clarifying the nature of and monoclonal antibodies in clarifying the nature of undifferentiated cell

23 Heil GE, Gunsilius E, Raghavachar C, et al. Ultra-structural demonstration of peroxidase expression in acute unclassified leukemias: Correlation to immunophenotype and treatment outcome. Blood 1991;77:1305-12.

24 Polli N, Lambertenghi-Deliliers G, Schiro R, et al. Relevance of ultrastructural immunocytochemistry in the characterization of unclassifiable leukemias: correlation with phenotypic and genic studies. Haematologica 1989;74:129-36. 